\title{
Organizational and technological solutions during the production facade works
}

\author{
Muhammad Fahratov*, Ibrahim F. Ibrahim \\ Moscow State University of Civil Engineering, 129337, Moscow, Russia,
}

\begin{abstract}
The article deals with the organizational and technological features of construction. Currently, based on foreign and domestic experience, a significant number of regulatory and methodological documents have been developed for the use of facade systems, but these works do not fully disclose organizational and technological issues and contain only general recommendations for the production of work. In particular, the existing recommendations for the installation of facade systems, for the most part, describe the constructive solutions of facade systems, technological issues related directly to the installation of the facade system, while not disclosing in sufficient detail the organization of the construction site, the issues of choosing the necessary means of paving, the issues of standardizing the labor intensity of work, issues of quantitative and qualitative selection of the composition of workers for the production of work. The organization of construction production for the installation of hinged facade systems with an air gap during the construction of buildings is associated with coordination with general construction works. Often, construction management projects developed at the design stage are adjusted taking into account the current conditions. These changes can occur both before the start of work and during the production of work. The introduction of organizational and technological changes in the production process of work can lead to a significant decrease in technical and economic indicators. In this regard, it is relevant to resolve the issues of assessment and selection of effective organizational and technological solutions for the device of facade systems.
\end{abstract}

\section{Introduction}

Companies associated with the use of hinged facade systems can be conditionally divided into several main groups: companies engaged only in the production and supply of individual elements of facade systems, companies - system holders engaged in the development of facade systems that have their own production, but do not specialize in installation, as the main type activities, while performing installation supervision of the system at small objects; companies performing a full range of work, from the production of system elements to installation; companies dealing only with the installation of the system.

*Corresponding author: eng.civil2004@gmail.com 
To date, there are two main options for constructive and technological solutions for external insulation systems of facades: composite facade thermal insulation systems with external plaster layers and hinged facade systems with an air gap. The choice of insulation method depends on many factors, incl. from the functional purpose and architectural features of the object, the economic feasibility of the external thermal insulation device, the construction area, the cost of the component elements of the system and its installation, the labor intensity and service life of the system. Another important criterion for choosing a method of insulating the facade of a building is the possibility of performing work at negative ambient temperatures, since when implementing city programs for comprehensive overhaul, the limitation of material and technical resources necessitates an even distribution of work throughout the year. Constructive solutions for the device of hinged facade systems have a wide variety of solutions that can be conditionally subdivided according to the cladding material and the material of the system substructure and its design features $[1,2,3,4]$.

On the type of objects on which hinged facade thermal insulation systems are installed, the largest part falls on administrative buildings and new construction of residential buildings (Fig. 5). When using the system on different types of buildings, special attention is paid to ensuring the required class of energy efficiency, fire safety and ensuring the required service life of the facade system.

Requirements and recommendations of normative and technical documents on façade systems can be conditionally divided into the following groups:

1) to the procedure for the development and composition of project documentation;

2) to the composition of organizational and technological documentation;

3 ) to the organization of the construction site (for the general case);

4) to the technical characteristics of the means of paving;

$5)$ to the technology of installation (recommendations);

6) requirements for labor safety $[5,6]$.

The above normative and technical documents regulating the requirements for the production of work give general recommendations for the organization of construction production and do not give instructions in sufficient detail for the choice of specific means of labor mechanization, means of paving, organizational and technological parameters for the production of work and the organization of the construction site in cramped conditions. As a rule, contractors performing the installation of the system as organizational and technological documents apply the recommendations of the system developers, which describe in detail the design solutions and technological requirements for the installation of standard products. Existing standard flow charts for installation and also provide solutions for a certain amount of work. The organization of construction production when installing hinged facade systems is associated with the need for coordination with general construction works. Often, the specified parameters of the construction organization project, developed at the design stage, are adjusted taking into account the current conditions. These changes can occur both before the start of work and during the production of work. Introduction of organizational and technological changes in the production process can lead to a significant decrease in technical and economic indicators $[7,8]$.

\section{Materials and methods}

The study of the issue was carried out on the basis of the analysis of theoretical data adopted in the organizational and technological documentation. During the study, a 
comparison of optimization methods was performed. Criteria assessment or application of a generalized indicator depends on the goals of the project and the tasks to be solved.

\section{Results}

Despite the fact that the process of mastering advanced technologies for thermal protection of buildings began a long time ago, the problem of manufacturing defects when performing work on insulation and finishing of facades, as before, remains one of the most important problems of modern construction. Moreover, if at the initial stage of introducing thermal insulation systems for external enclosing structures into domestic construction practice, a mass marriage could be attributed to imperfect technologies or a lack of professionalism of installers, today the unsatisfactory quality of facades is a consequence of a series of mistakes made by participants in the architectural and construction process at various stages of project $[9,10]$. This is largely due to the developing and immature construction market, in which dozens of companies have appeared that supply systems for protective and decorative finishing of buildings, and contractors that provide installation services, among which there are many companies whose main principle of production and commercial activity is to obtain profits by any means, including by saving on high-quality building materials, non-compliance with the production technology, low level of organization of construction production. The result of this approach is a low warranty for the work performed and frequent repairs. Factors that reduce the quality of work also include inaccurate geodetic breakdown of the facade and the receipt of incorrect information about the plane of the facade, due to inaccurate layout of the elements of the substructure and the protective screen. Thus, the analysis of typical errors in the installation of hinged facade systems showed that it is necessary to carry out appropriate quality control of the work performed and conduct periodic inspections. Erection quality management is an important part of the construction industry, as a result of which the projected safe life of the system is ensured.

Each of the above solutions has its own advantages and disadvantages, which are inextricably linked. Therefore, already at the design stage, a thorough analysis of various factors is required that determine the further choice of one or another type of wall structure. So, in addition to the usual thermotechnical characteristics, its vapor permeability, the presence and location of the "dew point", the processes of vapor transfer and the associated condensate fallout inside the wall structure are essential.

Requirements and recommendations of regulatory and technical documents for the device of the facade system can be conditionally divided into the following groups:

1) to the procedure for the development and composition of project documentation;

2) to the composition of organizational and technological documentation;

3 ) to the organization of the construction site (for the general case);

4) to the technical characteristics of the means of paving;

5) to the installation technology (recommendations);

6) requirements for labor safety $[9,10,11,12]$.

The organization of construction production when installing hinged facade systems is associated with a complex of works, the composition of which depends on the type of construction (construction, reconstruction or overhaul). To consider the main stages of the work on the example of the overhaul of apartment buildings. Insulation of external walls during major repairs of apartment buildings without resettlement of tenants is carried out in accordance with regulatory and technical documents.

The general procedure for organizing work when installing a facade system consists of the following stages: 
1) planning the overhaul;

2) preparation for design;

3) development of project documentation;

4) development of organizational and technological documentation;

5) approval of project documentation;

6) technical assessment of working documentation;

7) execution of works;

8) operation of the hinged facade system.

In preparation for the design of the production of work, it is necessary to identify the main participants and determine the interaction scheme. The customers of the overhaul of a residential building may be federal executive authorities or local self-government bodies, organizations managing a residential building, homeowners' associations, housing construction cooperatives, tenant-owners whose apartment building is in their direct management (provided that they are, including investors). A management company or city government acts as a technical customer, which determines options for organizing a major overhaul or reconstruction of a building.

On the basis of the survey, the general designer develops design documentation, which is agreed with the technical customer. The contractor carries out repair and construction work on the basis of an agreement with the customer, design documentation received from the customer and organizational and technological documents developed in-house and agreed with the operating organization. The main organizational and technological documents are the work production project and the technological map.

The project for the production of work during the overhaul of an apartment building must contain: the procedure for installing scaffolding, fences for the construction site and scaffolding, the procedure for arranging places for passage and passage; organization of an administrative and warehouse zone; sequence of delivery of building materials; garbage collection and removal procedure $[13,14,15,16]$.

The issues of the tightness of the construction site remain relevant, which directly determines the size of the household town and the area for storing building materials in compliance with the requirements for their storage. Despite the small number of workers in the installation of a hinged facade system, the use of compact household complexes is of no small importance, allowing the efficient use of a limited area. The distribution of material and labor resources depends on the intensity of financing, the mechanisms used, the dimensions of the building and the timing of the work. The choice of organizational and technological parameters for the production of work determines the further organization scheme and technology for the device of facade systems. The general organizational and technological scheme for the installation of facade systems is shown on Fig. 1. To determine the actual condition of the outer walls, a comprehensive examination of the technical condition of the outer walls of the building is performed. The purpose of a comprehensive examination of the technical condition of external walls is to determine the technical condition, to obtain a quantitative assessment of the actual indicators of the quality of structures (strength, resistance to heat transfer, etc.). In this case, the information received should be sufficient for carrying out a variant design of a major overhaul and the adoption of the possibility of further operation. Inspection of the technical condition of external walls is carried out in three stages:

-preparation for the survey;

-preliminary visual examination;

-detailed (instrumental) examination. 


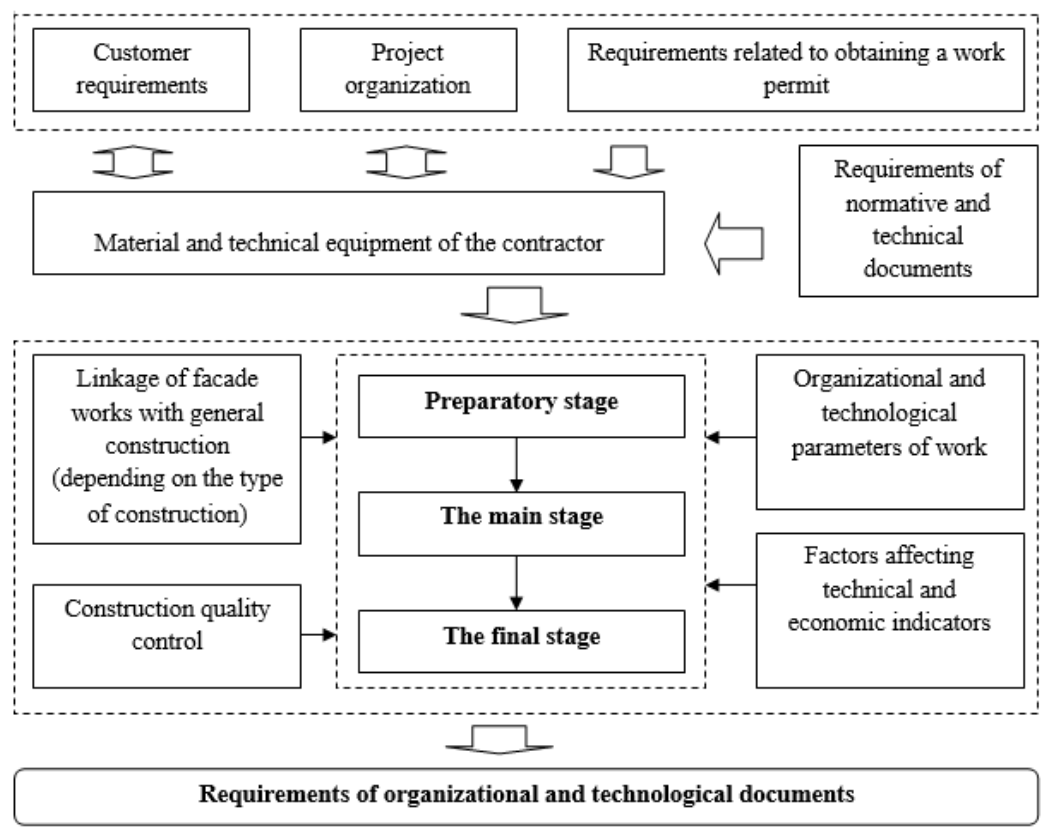

Fig. 1. Organizational diagram of the device of facade systems

Preparatory work for the survey is carried out in order to familiarize with the spaceplanning solution, collect and analyze design and technical documentation. A preliminary (visual) examination is carried out according to external signs for the need for a detailed (instrumental) examination.

On the basis of the survey, the general designer develops design documentation, which is agreed with the technical customer. The contractor carries out repair and construction work on the basis of an agreement with the customer, design documentation received from the customer and organizational and technological documents developed in-house and agreed with the operating organization.

After the development of the project documentation, it is necessary to make a number of approvals with government services. For designers, the main agreement is to obtain an opinion on the quality of design documentation. As a rule, construction work related to the occupation of an urban area (installation of scaffolding, construction of a community camp) requires coordination with the administrative and technical inspection of the city district and obtaining a work order. For this, the contractor, together with the customer, must prepare a set of documents according to the list determined by the relevant rules $[17,18]$.

In modern conditions, the development of an organizational and technological scheme precedes the development of organizational and technological documents and is necessary to select the most effective option for the production of work. Another purpose of the organizational and technological schemes is to give flexibility to the organization of construction. In the developing construction market, this feature acquires its relevance, because often, when the participants in the construction process interact, the failure to fulfill obligations by one of them entails changes in the general scheme of organization of construction production and the technological schemes for the device of facade systems acquire a special function of a backup option and is an effective way of making operational changes into the current construction industry. At the same time, the organizational and technological scheme is closely related to the concept of network planning. At this stage, 
decisions are made on the choice of means of mechanization, the sequence (stages) of work, the formation of teams of workers, ensuring the safety of work and other organizational and technological parameters. The decision is made on the basis of a study of the working project, analogs, as a result of studying local conditions, after performing calculations and preliminary studies, etc. The volume and depth of preliminary studies depend on the contractor's own experience. The result of the analysis of the information obtained is the schemes for the production of work with various degrees of detail on the device of hinged facade systems.

The complex of preparatory work, depending on the type of construction (new construction, reconstruction, overhaul), in each case has its own composition. Improving the organizational and technological processes of the preparatory period and the development of alternative options is necessary to ensure that the selected solutions correspond to the conditions of work. Features of the production of work are reduced to two main cases:

1) new construction;

2) reconstruction (table 1).

Table 1. Features of the organization of construction production when installing facade systems

\begin{tabular}{|c|l|l|}
\hline \multirow{2}{*}{ № } & \multicolumn{1}{|c|}{ Organizational and technological conditions for the production of work } \\
\hline 1 & $\begin{array}{l}\text { new construction } \\
\begin{array}{l}\text { coordination of works on the installation of } \\
\text { the facade system with a complex of works } \\
\text { on the construction of the entire facility } \\
\text { application of network planning) }\end{array}\end{array}$ & $\begin{array}{l}\text { reconstruction (overall repair) } \\
\text { the facade of works on the installation of } \\
\text { on the reconstruction of the object } \\
\text { (overhaul) }\end{array}$ \\
\hline 2 & $\begin{array}{l}\text { selection of technological equipment for } \\
\text { work at a height of mainly up to 150m }\end{array}$ & $\begin{array}{l}\text { selection of technological equipment for } \\
\text { work at a height, mainly up to 60m; }\end{array}$ \\
\hline 3 & $\begin{array}{l}\text { the level of constraint, as a rule, is } \\
\text { significantly lower than during } \\
\text { reconstruction }\end{array}$ & $\begin{array}{l}\text { cramped conditions of the construction site. } \\
\text { Mostly the work is carried out in urban } \\
\text { conditions of dense existing buildings }\end{array}$ \\
\hline 4 & $\begin{array}{l}\text { the possibility of free temporary storage of } \\
\text { material inside the facility and on the site } \\
\text { temporary storage sites, as a rule, are located } \\
\text { on the territory of the reconstructed facility }\end{array}$ \\
\hline 5 & $\begin{array}{l}\text { work production time is limited by the } \\
\text { requirements of regulatory and technical } \\
\text { documents }\end{array}$ & $\begin{array}{l}\text { as a rule, work is performed in one shift, it is } \\
\text { necessary to agree with the organization } \\
\text { operating the facility (depending on the } \\
\text { operating mode of the enterprise or } \\
\text { residents) }\end{array}$ \\
\hline 6 & $\begin{array}{l}\text { before starting work, you must have an act } \\
\text { of acceptance of the basis }\end{array}$ & $\begin{array}{l}\text { before starting work, it is necessary to } \\
\text { inspect the enclosing structures in } \\
\text { accordance with }\end{array}$ \\
\hline 7 & $\begin{array}{l}\text { uniform consumption of materials } \\
\text { throughout the object }\end{array}$ & $\begin{array}{l}\text { material consumption depends on the state } \\
\text { (plane) of the wall }\end{array}$ \\
\hline 8 & $\begin{array}{l}\text { ready-made base for the installation of the } \\
\text { facade system }\end{array}$ & $\begin{array}{l}\text { additional work on the preparation (repair) } \\
\text { of walls, including the removal of fragile } \\
\text { plaster, restoration of brick and masonry }\end{array}$ \\
\hline
\end{tabular}

As can be seen from the table, the organizational and technological conditions for the production of work during reconstruction (overhaul) have some limitations and difficulties that must be taken into account when designing the organization of work on the installation of the facade system.

\section{Conclusion}


Thus, the task of adjustment is reduced to the compilation of an optimal work schedule, ensuring the greatest uniformity of resource schedules. The correct adjustment of the schedules is based on the calculation of the coefficients and parametric indicators of the resource schedules. Comparing them with normal indicators, we can conclude that the optimization was successful. The analysis of the influencing factors showed that one of the most important issues in the design of work is the choice of the necessary means of paving and the analysis of the conditions for the production of work. The mechanism for making scientifically grounded decisions depends on the assessment of the impact of the decisions made on the technical and economic performance of the work. In modern conditions, when preparing construction production, it is no longer enough to have a lot of practical experience. Effective and well-grounded decisions can be made only on the basis of a variant design, taking into account the analysis of previously applied design and organizational and technological solutions in order to reduce the labor intensity, cost and duration of construction. At the same time, the greatest difficulty is the assessment of factors that have different dimensions of quantitative and qualitative indicators $[19,20]$.

The choice of one or another solution depends on factors that can be combined into three main groups:

1) the determining initial factors are customer requirements; requirements of regulatory and technical documents; terms of delivery of components; requirements related to obtaining a work permit, material and technical support of the contractor, geometric characteristics of the object, constructive solution of the facade system;

2) determining direct factors that have a direct impact on the technical and economic indicators - the organizational and technological parameters of the work;

3 ) indirect factors that do not have a direct impact, but indirectly affect the technical and economic indicators - the tightness of the construction site and the climatic conditions of the work.

Depending on the degree of influence of certain factors, the organizational and technological parameters of the work production also change.

To assess the factors affecting the main technical and economic indicators, the method of expert assessments was applied. The essence of this method is that experts conduct an intuitive-logical analysis of the problem with the assessment of judgments and formal processing of the results. The generalized opinion of experts obtained as a result of processing is accepted as a solution to the problem. Typical tasks solved using the method of expert assessments include: defining the goals and objectives of management with ordering them in order of importance, identifying alternative tasks with an assessment of their preferences, alternative allocation of resources for solving problems with an assessment of their preference, options for making decisions in a certain situation with an assessment of their preference.

\section{References}

1. A. Lapidus, I. Abramov, IOP Conference Series: Materials Science and Engineering, 365(6), 062002 (2018)

2. A.A. Lapidus, N.Yves, Materials Science Forum 931, 1295-1300 (2018)

3. D.V. Topchy, A.A. Lapidus, E3S Web of Conferences 91, 08044 (2019)

4. A. Lapidus, T. Dmitry, IOP Conference Series: Materials Science and Engineering, 471(2), 022034 (2019)

5. A. Lapidus, Y. Shesterikova, E3S Web of Conferences 91, 02025 (2019) 
6. A. Lapidus, I. Abramov, IOP Conference Series: Materials Science and Engineering 603, 052079 (2019)

7. S.A. Sinenko et al., Automation of organizational and technological design in construction (Saratov, Higher education, 2019)

8. B.V. Zhadanovsky et al., Technology and organization of construction production 1, 38-40 (2014)

9. A. Lapidus, I. Abramov, Collection of materials from a seminar held as part of the VI International Scientific Conference 463(3), 159-162 (2018).

10. A. Lapidus, I. Abramov, MATEC Web of Conferences 193, 05033 (2018)

11. P.P. Oleinik, Industrial and civil construction 6, 46-50 (2019)

12. L.A. Pakhomova, P.P. Oleinik, Technology and organization of construction production 1, 49-52 (2019)

13. P. Oleinik P. et al., MATEC Web of Conferences 193, 05037 (2018)

14. B.V. Zhadanovsky et al., Stream method as a way of organizing the construction of System Technologies 3(28), 136-140 (2018)

15. A.A. Zelentsov, A.Ya. Tokarsky, Collection of reports of a scientific and technical conference based on the results of research work by students of the Institute of Construction and Architecture, 1361-1363 (2019)

16. A.A. Lapidus et al., Science and business: development paths 6 (84), 18-22 (2018)

17. M.I. Solomatina, Collection of reports of a scientific and technical conference based on the results of research work by students of the Institute of Construction and Architecture, 1299-1301 (2019)

18. J. Liu, M. Lu, Journal of Construction Engineering and Management 146(5), (2020) doi:10.1061/(ASCE)CO.1943-7862.0001813.

19 M. Arashpour et al, Automation in Construction 95, 19(2018)doi:10.1016/j.autcon.2018.07.027.

20. Q.Sun, D. Li, Y. Ren, Tiedao Xuebao, Journal of the China Railway Society 40(12), 101-107 (2018) doi:10.3969/j.issn.1001-8360.2018.12.013. 